\title{
The lacI transgenic mouse mutagenicity assay: quantitative evaluation in comparison to tests for carcinogenicity and cytogenetic damage in vivo
}

\author{
Sarah E. Shephard *, Werner K. Lutz, Christian Schlatter \\ Institute of Toxicology, Swiss Federal Institute of Technology and University of Zürich, CH-8603 Schwerzenbach, Switzerland
}

(Received 16 June 1993)

(Revision received 20 October 1993)

(Accepted 21 October 1993)

\begin{abstract}
The detection limit of the lacI transgenic mouse mutagenicity assay lies, in practice, at approximately a 50-100\% increase in mutant frequency in treated animals over controls. The sensitivity of this assay in detecting genotoxins can be markedly improved by subchronic rather than acute application of the test compound. The lacI transgenic mouse mutagenicity assay was compared quantitatively to rodent carcinogenicity tests and to presently used in vivo mutagenicity assays. With the genotoxic carcinogens tested thus far, a rough correlation between mutagenic potency and carcinogenic potency was observed: on average, to obtain a doubling in lacI mutant frequency the mice had to be treated with a total dose equal to 50 times the $\mathrm{TD}_{50}$ daily dose level. This total dose could be administered either at a high dose rate within a few days or, preferably, at a low dose rate over several weeks. This analysis also indicated that a lacl experiment using a 250-day exposure period would give a detection limit approximately equal to that of a long-term carcinogenicity study. In comparison to the micronucleus test or the chromosome aberration assay, acute studies with the presently available lacI system offered no increase in sensitivity. However, subchronic lacI studies (3-4-month exposure) resulted in an increase in sensitivity over the established tests by 1-2 orders of magnitude (shown with 2-acetylaminofluorene, $N$-nitrosomethylamine, $N$-nitrosomethylurea and urethane). It is concluded that a positive result in the lacI test can be highly predictive of carcinogenicity but that a negative result does not provide a large margin of safety.
\end{abstract}

Key words: Transgenic mice; Mutagenicity assay; Sensitivity; Chromosome aberration; Micronucleus test; Carcinogenic potency

\footnotetext{
* Corresponding author. Tel. +41-1-825 73 56; Fax: +41-18250476 .
}

\begin{abstract}
Abbreviations: LED, lowest effective dose; $\mathrm{TD}_{50}$, tumour dose 50\%; DD, doubling dose; pfu, plaque forming units; BG, background; SD, standard deviation.
\end{abstract}

0027-5107/94/\$07.00 ㅇ 1994 Elsevier Science B.V. All rights reserved SSDI 0027-5107(93)E0205-5 


\section{Introduction}

The advent of transgenic technology has opened up exciting new possibilities for mutagenicity testing in mammals. Using the bacterial lacI gene as a reporter gene, transgenic mice have been constructed that could allow genotoxic agents to be examined in vivo in practically any desired target organ (Kohler et al., 1990). A description of the assay is given in Fig. 1.

Questions surrounding the assay at present include (1) what dose levels are necessary to induce measurable effects, (2) in what range do the spontaneous and induced mutant frequencies lie, (3) what factors influence the detection limit of the test, and (4) how do the sensitivity and specificity of the assay compare with the other in vivo systems for detecting mutagenicity or carcinogenicity?

1.

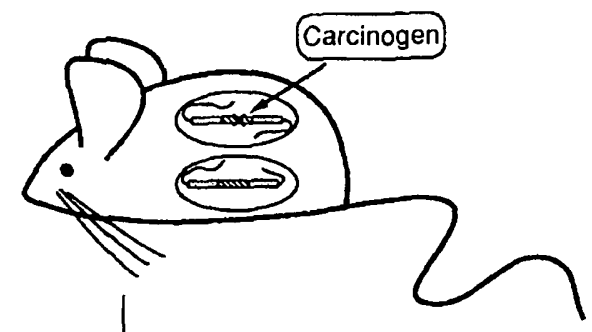

2.

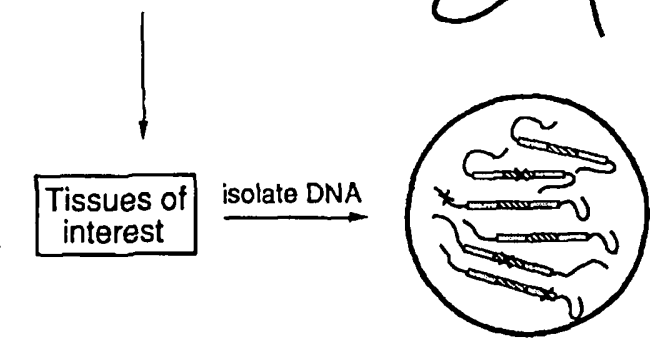

3.
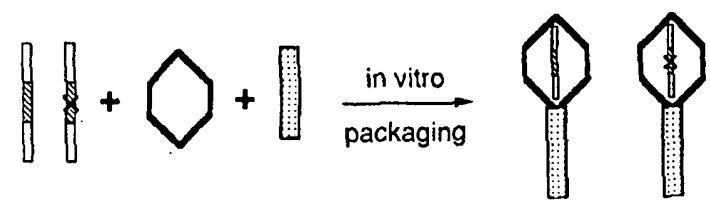

4.

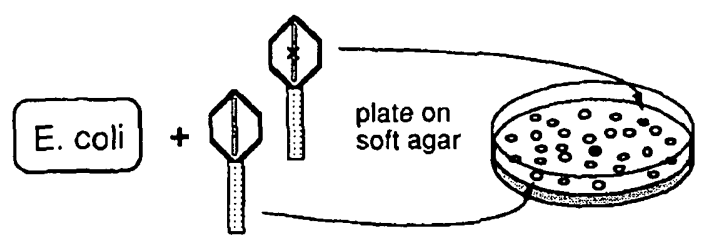

In this review, results of lacl studies from the literature (Kohler et al., 1991a,b) and from our own studies (Gunz et al., 1993; Shephard et al., 1993; unpublished data) have been compiled and compared to results on the same compounds in long-term rodent bioassays, the micronucleus and chromosome aberration tests (metaphase analysis) in vivo. The emphasis is on a quantitative comparison of the sensitivities of the test systems. In addition, factors which affect the limit of detection of the lacl assay are examined, both those which can be influenced by experimental design and those inherent in the system.

\section{Methods}

\subsection{LacI mutagenicity assay data}

Experiments involving both acute ( 1 or 5 days) and subchronic (1, 3 or 4 months) exposure to test chemicals were included in this analysis. For each compound and exposure period tested, the lowest dose leading to a significant increase in

Fig. 1. Principle of the lacl mouse mutagenicity assay. (1) The genome of the mice contains multiple copies of a lambda vector (bars) bearing the lacl gene (striped), stably inserted into an autosomal chromosome. If the mice are exposed to genotoxins, there is a small probability that a mutation will occur somewhere along the inserted sequence (symbolised by an $X$ ). (2) Genomic DNA is purified from organs of interest. (3) The lambda vector bearing the target gene is excised from the genomic DNA and packaged in vitro into infective lambda bacteriophage particles. This step is accomplished by mixing the genomic DNA with a commercially available packaging extract that contains all the enzymes and the virus coat proteins necessary to excise the vector and build the phage particles. (4) The particles are allowed to infect an excess of $E$. coli bacteria. On agar plates, plaques from infected bacteria show up as holes against a lawn of uninfected bacteria. Mutations in the marker lacI gene are detected using a simple colour test: the lacl gene encodes a protein that represses expression of lac $Z$, a bacterial gene which codes for the enzyme $\beta$-galactosidase ( $\beta$-gal). If the lacI repressor is inactivated by a mutation, lac $Z$ will be transcribed in the host bacteria and $\beta$-gal activity expressed. $\beta$-Gal activity is detected with the chromogenic substrate X-Gal, which makes a blue product upon cleavage. On the agar plates one thus finds isolated blue plaques containing the mutated target gene amongst a vast majority of colourless plaques bearing the intact repressor. 


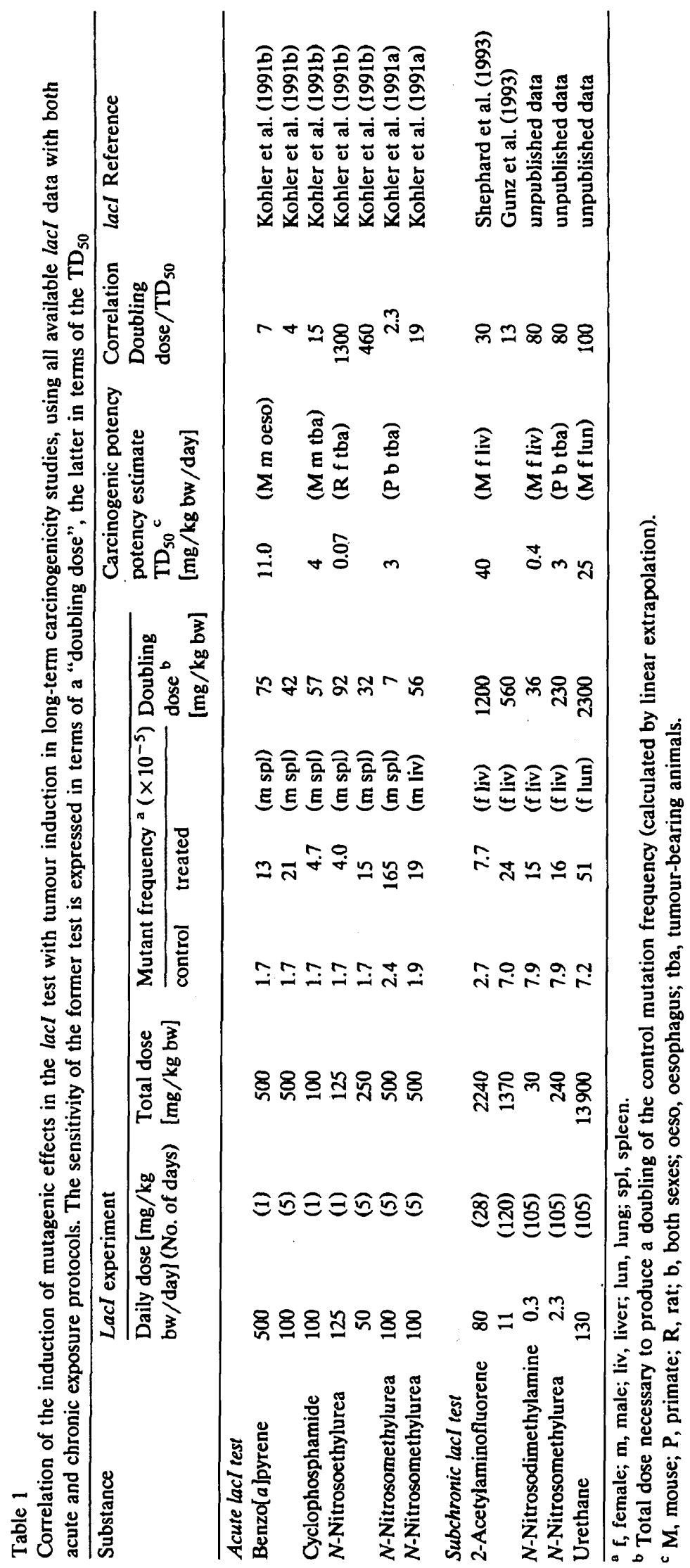


mutant frequency was compiled. Where data from more than one organ or more than one expression period (period between dosing with carcinogen and killing the animal) were available, the highest observed mutant frequency is reported here. The expression period in the acute studies was typically 1-12 days; no additional expression period following dosing was used in the chronic studies. Note that in some cases only one dose level was tested.

\subsection{Micronucleus test and chromosome aberration data}

A description of the two mutagenicity tests is provided in two reviews (Preston et al., 1981; Heddle et al., 1983). Data on all the compounds that have also been tested in lacI mice were compiled from the original literature; the specific references consulted are noted in Table 3 . The lowest dose leading to a significant increase in micronuclei or chromosome aberrations (LED, lowest effective dose) was recorded. Where data from more than one study were available, the geometric mean of the LEDs was calculated. Mouse data were used wherever possible; if lacking, rat data were taken as substitute. In some cases only one dose level was mentioned in the publications.

\subsection{Carcinogenic potency estimates}

An estimate of the carcinogenic strength of the compounds was found in the carcinogenicity potency data base of Gold et al. (1991). In this data base, the results of long-term rodent bioassays have been summarised, and a measure of the potency of each compound is given as the $\mathrm{TD}_{50}$. The $\mathrm{TD}_{50}$ is defined as the daily dose of a chemical (per kg body weight per day) that results in a $50 \%$ decrease in the number of tumour-free animals after lifetime exposure (2 years in rats and mice). The appropriate $\mathrm{TD}_{50}$ value was selected from the data base according to the following hierarchy of criteria: (1) increase in tumour incidence statistically significant $(P<0.05)$; (2) mouse as test species; (3) same sex as in mutagenicity study; (4) malignant tumours rather than benign;

Table 2

Variation in lacl mutant frequency in the liver amongst animals of the same treatment group (data from Gunz et al., 1993)

\begin{tabular}{|c|c|c|c|c|}
\hline Treatment & $\begin{array}{l}\text { Plaques } \\
\text { counted }\end{array}$ & $\begin{array}{l}\text { Mutant } \\
\text { plaques }\end{array}$ & $\begin{array}{l}\text { Mutant frequency } \\
\pm \text { Poissonian error } \\
\left(\times 10^{-5}\right)\end{array}$ & $\begin{array}{l}\text { Mean mutant } \\
\text { frequency } \pm S D \\
\left(\times 10^{-5}\right)\end{array}$ \\
\hline Control group 1 & $\begin{array}{l}212050 \\
163880 \\
191370 \\
165080\end{array}$ & $\begin{array}{r}13 \\
14 \\
19 \\
9\end{array}$ & $\begin{array}{l}6.1 \pm 1.7 \\
8.5 \pm 2.3 \\
9.9 \pm 2.3 \\
5.5 \pm 1.8\end{array}$ & $7.5 \pm 2.1$ \\
\hline Control group 2 & $\begin{array}{l}193600 \\
170265 \\
177200\end{array}$ & $\begin{array}{l}11 \\
20 \\
24\end{array}$ & $\begin{aligned} 5.7 & \pm 1.7 \\
12 & \pm 3 \\
14 & \pm 3\end{aligned}$ & $10 \pm 4$ \\
\hline 2-AAF $75 \mathrm{ppm}$ & $\begin{array}{r}148500 \\
82195 \\
153600\end{array}$ & $\begin{array}{l}53 \\
18 \\
37\end{array}$ & $\begin{array}{l}36 \pm 5 \\
22 \pm 5 \\
24 \pm 4\end{array}$ & $27 \pm 8$ \\
\hline 2-AAF $150 \mathrm{ppm}$ & $\begin{array}{r}157350 \\
92650 \\
73200\end{array}$ & $\begin{array}{l}82 \\
28 \\
49\end{array}$ & $\begin{array}{l}52 \pm 6 \\
30 \pm 6 \\
67 \pm 10\end{array}$ & $51 \pm 20$ \\
\hline
\end{tabular}

Each line represents one animal. The Poissonian error of each mutant frequency estimate is given for each individual animal ( \pm 1 SD); the biological variability in each treatment group is expressed as the standard deviation around the mean. 
(5) $\mathrm{TD}_{50}$ value for same organ as examined in mutagenicity study; (6) 2-year rather than a shorter exposure period. If the available data did not meet all the criteria, the data used to calculate the $T D_{50}$ were selected by waiving first the sixth criterion, next the fifth, and so on until the first satisfactory data set was found.

\subsection{Calculations and statistics}

The "doubling dose" (DD) was defined as the total dose of carcinogen (daily dose integrated over treatment period) that would induce a mutant frequency double that of control animals, assuming a linear dose response in the net mutant frequency. The doubling dose was calculated from the lacl mutant frequencies in Table 1 according to the following formula: $\mathrm{DD}=$ (total dose of carcinogen)/[(induced - spontaneous mutant frequency)/(spontaneous mutant frequency)].

The confidence intervals for the mutant frequencies given in Table 2 were calculated assuming a Poisson distribution (Werner, 1984):

$k /\left(n \times F_{[\infty, 2 \mathrm{k}]}\right) \leq p \leq\left[(k+1) \times F_{[2(\mathrm{k}+1), \infty]}\right] / n$

where $p=$ real mutant frequency, $k=$ number of mutants, $n=$ total number of plaque forming units (pfu) counted, $F_{\mathrm{f} 1, \mathrm{f} 2}=$ uncertainty factors from 2sided F-distribution table for $\alpha=0.05$.

\section{Results and discussion}

A summary of lacI experiments and results published thus far is given in Table 1 , columns 1-4. Spontaneous mutant frequencies vary somewhat between labs, lying in the range of $2-8 \times$ $10^{-5}$ (column 3). At the doses chosen in these studies, induced mutant frequencies generally lay approximately $2-10$-fold above the spontaneous values.

\subsection{Accumulation of mutations in subchronic stud- ies}

It is apparent that in the acute studies (1-5 days) massive doses of carcinogen were necessary to produce a measurable effect; doses administered are often in the range of overt toxicity. Considerably smaller doses gave significant effects in the subchronic studies (28-120 days), due to an accumulation of mutations over the exposure period. In the liver, an increase in sensitivity of the test was possible over quite a long time

Table 3

Comparison of the lowest reported daily doses of genotoxins (in $\mathrm{mg} / \mathrm{kg}$ bw) that give statistically significant results in the lacI system vs. two standard in vivo mutagenicity tests (mouse data unless stated otherwise)

\begin{tabular}{|c|c|c|c|c|c|c|}
\hline \multirow{2}{*}{$\begin{array}{l}\text { Substance } \\
\text { Acute lacI data } \\
\text { Benzo[ } a \text { ]pyrene }\end{array}$} & \multicolumn{2}{|c|}{$\begin{array}{l}\text { LacI assay a } \\
\text { (No. of days, organ) }\end{array}$} & \multicolumn{2}{|c|}{$\begin{array}{l}\text { Micronucleus test } \\
\text { (Reference) }\end{array}$} & \multicolumn{2}{|c|}{$\begin{array}{l}\text { Chromosome aberrations } \\
\text { (Reference) }\end{array}$} \\
\hline & $\begin{array}{l}500 \\
100\end{array}$ & $\begin{array}{l}(1, \mathrm{spl}) \\
(5, \mathrm{spl})\end{array}$ & 44 & (Heddle et al., 1983) & 145 & (rat; NIOSH, 1987) \\
\hline Cyclophosphamide & 100 & $(1, \mathrm{spl})$ & 38 & (IARC, 1987) & 13 & ("animal”; IARC, 1987) \\
\hline$N$-Nitrosoethylurea & $\begin{array}{r}125 \\
50\end{array}$ & $\begin{array}{l}(1, \mathrm{spl}) \\
(5, \mathrm{spl})\end{array}$ & 140 & (rat; Tates et al., 1986) & 100 & (Soukup and $\mathrm{Au}, 1975$ ) \\
\hline$N$-Nitrosomethylurea & 100 & $(5, \mathrm{spl})$ & no data & & 8 & (Frei and Venitt, 1975) \\
\hline \multicolumn{7}{|l|}{ Subchronic lacI data } \\
\hline 2-Acetylaminofluorene & $\begin{array}{l}80 \\
11\end{array}$ & $\begin{array}{r}(28, \text { liv }) \\
(120, \text { liv })\end{array}$ & 270 & $\begin{array}{l}\text { (Friedman and Staub, 1977; } \\
\text { Heddle et al., 1983) }\end{array}$ & 30 & $\begin{array}{l}\text { (rat, } 21 \text { day exp.; } \\
\text { Hitachi et al., 1975) }\end{array}$ \\
\hline$N$-Nitrosodimethylamine & 0.3 & $(105$, liv) & 44 & $\begin{array}{l}\text { (Friedman and Staub, 1977; } \\
\text { Watanabe et al., 1982; } \\
\text { Heddle et al., 1983) }\end{array}$ & 23 & $\begin{array}{l}\text { (rat; IARC, 1978; } \\
\text { NIOSH, 1987) }\end{array}$ \\
\hline$N$-Nitrosomethylurea & 2.3 & $(105$, liv $)$ & no data & & 8 & (Frei and Venitt, 1975) \\
\hline Urethane & 130 & (105, lun) & 220 & (Heddle et al., 1983) & 5000 & (Colnaghi et al., 1969) \\
\hline
\end{tabular}

liv, liver; lun, lung; spl, spleen. 
period: after a 28-day exposure to 2-AAF, a dose of $80 \mathrm{mg} / \mathrm{kg} /$ day was required to produce a 3-fold increase in mutant frequency, whereas after 120 days' exposure, $11 \mathrm{mg} / \mathrm{kg} /$ day sufficed to produce a 3.5 -fold increase. The induced mutant frequency was roughly proportional to the integral of dose over time, i.e., the effect depended primarily on the total dose administered, independent of the dosing schedule. A similar additive effect of repeated mutagen treatments has been observed with the compounds $N$ nitrosoethylurea, methyl methanesulfonate and 1,2-dimethylhydrazine in experiments using the Dlb-1 locus as marker (Tao and Heddle, 1994).

That subchronic dosing allows the effects of small doses of mutagens to be detected could be important for the toxicological interpretation of the results. At high doses, overt toxicity can induce regenerative hyperplasia and reduce the time available for repair enzymes to remove DNA damage before it becomes fixed as mutations. Similarly, DNA repair capacities can be saturated or exhausted by high doses. The linear relationships seen above do not hold true under these circumstances (Russell et al., 1982). Results of such experiments are more difficult to use for extrapolation down to low-dose human exposure levels.

\subsection{Correlation between lacl results and carcino-} genic potency

The $\mathrm{TD}_{50}$ was used as a standard measure of potency of carcinogens (Table 1, column 6); for the lacl data, a DD was defined as a measure of potency (column 5). The definitions of both units are given in the Methods section. The DDs are compared to $\mathrm{TD}_{50}$ values in column 7 . The correlation between mutagenic potency and carcinogenic potency is rather poor for the acute lacI data, the ratios $\mathrm{DD} / \mathrm{TD}_{50}$ vary over a wide range, from 2.3 to 1300 . With the subchronic lacl data the $\mathrm{DD} / \mathrm{TD}_{50}$ ratios are much more uniform and lie between 13 and 100 , i.e., within one order of magnitude of each other. The geometric mean of the ratios is 47 .

The selection of test substances and routes of administration can partly explain this difference in the correlations: mouse carcinogenicity data were available for most of the compounds selected for chronic lacI studies, whereas only rat or primate carcinogenicity data were available for some of the compounds tested in the acute lacl studies. In acute studies the animals were usually dosed i.p., whereas in the carcinogenicity and subchronic lacl studies the substances were administered in the feed or drinking water. A tighter correlation would be expected for the acute data if these factors matched.

Certain other important factors related to the experimental protocol, the doses used and the organs examined in the acute and subchronic lacI studies could also bear upon the correlation to carcinogenic potency: the selection of an appropriate expression period becomes less critical if dosing is chronic, and factors such as cytotoxicity that can indirectly influence the mutant frequency are also less important at the lower doses used in the long-term treatment (cf. previous section). Furthermore, examining mutants in the target organs would be expected to give a better correlation to carcinogenicity than using the spleen as a "marker organ".

The rough correlation derived here between carcinogenic potency and mutagenicity in the lacI system predicts that a daily dose of genotoxin which produces a $50 \%$ tumour incidence after 2 years should produce an approximately $100 \%$ increase in lacl mutant frequency after about a 50-day exposure period. This information could be useful in setting dose levels for future lacI studies. With the knowledge that, roughly speaking, a total dose of $50 \times \mathrm{TD}_{50}$ will result in a doubling of the mutant frequency, the experimental design can include the appropriate dose groups and exposure periods to produce statistically significant results. This correlation will also be used below in the comparison of the limits of detection of lacI and carcinogenicity tests.

\subsection{Limit of detection of a mutagenic effect in the lacI test}

The detection limit of the lacl test is influenced by several independent factors: (i) the background mutant frequency, (ii) the number of 
plaques examined per animal, (iii) the animal-toanimal variation in response to the mutagen, and (iv) the number of animals per group. Factors (ii) and (iv), in turn, are limited by reagent and labour costs.

Since the frequency of mutants is extremely small, the data from each animal are expected to follow a Poisson distribution (Spiegel, 1990; to date, no significant deviation from a Poisson distribution has been reported for data from individual animals (W. Piegorsch, personal communication, 1993)). As a consequence, the standard deviation (SD) of a mutant count is approximated by its square root. It therefore requires less effort to reach significance for a doubling of the mutant frequency (100\% increase) in a tissue with a high background (BG) mutation rate than in one with a low natural rate. In a hypothetical case, based on a Poisson distribution of the data and disregarding animal-to-animal variation, a doubling of mutant frequency is significant at $95 \%$ confidence once 14 mutants $(S D= \pm 3.7)$ have been registered in the control sample and $28(\mathrm{SD}= \pm 5.3)$ in the treated sample, independent of whether the 14 are found amongst 200000 or 700000 wild-type sequences (BG $=7 \times 10^{-5}$ or $2 \times 10^{-5}$, respectively). For a detection limit of $50 \%$ increase, the Poisson distribution requires that 42 and 63 mutants be accumulated in control and treated samples, respectively (requires examination of 600000 when $\mathrm{BG}=7 \times 10^{-5}$ or $2.1 \mathrm{mil}$ lion plaques at a background of $2 \times 10^{-5}$ ). From a purely mathematical standpoint, the limit of detection that can be achieved depends primarily upon the effort one is willing to put into analysing plaques.

The other main source of variability is the biological variation in response between individual animals of the same treatment group; this follows a normal distribution. Within one experimental group, variations by a factor of 2 are not unusual (Table 2). The effect of this variation can be mitigated by (i) increasing the number of animals per group and (ii) counting enough plaques per animal to provide a reasonably precise estimate of individual mutant frequencies. Table 2 illustrates the relative importance of these two sources of error (Poissonian or "counting" error vs. standard deviation around the mean of one treatment group) in typical data from a lacl experiment in our lab. At these numbers of plaques (70 000-200000 analysed per sample), both sources of variation contribute approximately equally to the error in the control groups, whereas the biological variability dominates in the treated groups. A comprehensive statistical analysis of all aspects of the test, both biological and technical, that can contribute to variability in the data is currently in progress in other research groups.

Limitations on the number of plaques counted are primarily given by the not inconsiderable costs of reagents, materials and labour. As the lacl test is currently conducted in our lab, one person can prepare, package and analyse about $10^{6}$ plaques per work week. Depending on the packaging efficiency of the tissue being examined (in our hands: lung, glandular stomach $>$ kidney $>$ forestomach, liver $>$ bladder) and the quality of the particular DNA sample, it presently costs US\$700-2500 in reagents and materials to produce $10^{6}$ plaques (not including the animals themselves). However, it is likely that the test will become more economical in the future once selectable systems and innovations to increase packaging yield and recycle materials are introduced.

We have developed a pragmatic strategy to optimise the use of resources. (1) More plaques are counted from control than from treated animals. (2) After each round of packaging we calculate the confidence interval for each mutant frequency, where the present limit of detection lies, and analyse with statistical methods whether an effect has reached statistical significance. We stop packaging a particular sample once (i) an effect is detectable at the desired level of statistical significance, or (ii) the desired limit of detection has been reached. Given all the above variables, our practical limit of detection at the moment lies between a 50 and $100 \%$ increase in mutant frequency.

\subsection{Sensitivity of lacI test vs. established muta- genicity tests}

The lacI system was compared quantitatively to two of the most frequently used in vivo assays 
for cytogenetic damage: the micronucleus test and the chromosome aberration assay. For each compound that has been examined with lacI mice, the lowest dose leading to a significant result in each test system has been compiled (Table 3 ). In some cases only one dose was recorded in the original literature, in these cases the true limit of detection is probably somewhat lower.

Evident from the table is that in acute studies, lacI offers no sensitivity advantage over the established assays. The doses of mutagen necessary to give a positive result in each of the test systems were quite similar. This result was somewhat unexpected, as this particular group of test chemicals would be expected to preferentially cause gene mutations rather than chromosome aberrations, and considering that the chromosome aberration and micronucleus tests detect damage in a marker tissue rather than in the target organ. However, the explanation lies at least partly in the different background mutation levels in the two types of test: note that the unit of analysis in the lacI test is the gene, whereas the cell is the unit of analysis for the micronucleus and chromosome aberration assays. If the background frequency of gene mutations observed in the lacI test is extrapolated and expressed as number of events per cell, one arrives at approximately: $\left(5 \times 10^{-5}\right.$ mutations per gene $) \times\left(10^{5}\right.$ genes per cell $)=5$ mutation events per cell.

Our detection limit would thus correspond to 7.5-10 mutation events per cell. In contrast, the background rate of, e.g., micronucleus formation is $\approx 2$ events $/ 1000$ cells; the limit of detection is a doubling or tripling of mutant frequency to 4-6 events $/ 1000$ cells (Heddle et al., 1983). Background rates and detection limits in chromosome aberration assays are similar or slightly higher (Preston et al., 1981). The lower background rates of the micronucleus and chromosome aberration assays allowed these tests to detect smaller absolute numbers of mutation events per cell (about 3 orders of magnitude less).

In contrast to the above, in chronic studies the lacl test does offer an increase in sensitivity 1-2 orders of magnitude above the standard chromosome aberration and micronucleus tests, at least for these types of mutagen. For example, $N$ - nitrosodimethylamine produced detectable genotoxicity in the lacI test at a daily dose of only 0.3 $\mathrm{mg} / \mathrm{kg}$ over 105 days, whereas doses of $44 \mathrm{mg} / \mathrm{kg}$ and $23 \mathrm{mg} / \mathrm{kg}$ were necessary to produce a "positive" in the standard micronucleus and chromosome aberration assays (Table 3 ). It is to be hoped that the sensitivity advantage offered by longer exposure times will be exploited in the future.

\subsection{Limit of detection of the lacI test us. long-term rodent carcinogenicity studies}

In rodent carcinogenicity studies, the detection limit depends on the size of the study (number of animals used) and the spontaneous tumour incidence: for example, in a study with 40 control and 40 treated animals and a spontaneous tumour incidence of $1 \%$, the detection limit (95\% confidence limit) would lie at a $10 \%$ increase in tumours (i.e., $\approx \mathrm{TD}_{10}$; Cairns, 1979). We will assume here that this tumour incidence is induced at a dose rate of one-fifth of the $\mathrm{TD}_{50}$.

The detection limit of the lacI test in our hands lies at a $50-100 \%$ increase in mutant frequency. For this comparison we will assume that a doubling in mutant frequency can be reliably detected in any desired tissue. The rough correlation between lacI results and carcinogenic potency derived from the results in Table 1 showed that a doubling in mutant frequency in the lacl system could be obtained if a dose equivalent to the $\mathrm{TD}_{50}$ was administered daily for $\approx 50$ days. Furthermore, the data with 2-AAF (Table 1) indicated that the sensitivity of the lacI test could be increased by lengthening the treatment period. It therefore follows that a detection limit equivalent to $\mathrm{TD}_{10}$ might be achieved in the lacl test if exposure periods 5 times longer were to be used (i.e., 250-day exposure at $\mathrm{TD}_{10}$ level $=50$-day exposure at $\mathrm{TD}_{50}$ level $=$ detection limit in lacI test).

The following points can be derived from this preliminary comparison of detection limits.

(1) The lacl system as a short-term test (acute dosing) is less sensitive than classical carcinogenicity studies.

(2) A lacl study with a genotoxic chemical given 
at the maximum tolerated dose for 250 days might offer a similar sensitivity as a 2 -year carcinogenicity study.

(3) If a positive result is seen in a high-dose 1-5-day lacl experiment, carcinogenicity in rodents could be expected after exposure to daily dose levels 50-250-fold below the acute dose. Such a positive result could be informative for the prediction of carcinogenic potency.

(4) A negative result in an acute lacI test offers only a modest margin of safety: a 50-250-fold lower daily dose could still produce a measurable increase in tumour incidence in a longterm study.

(5) The element of exposure period can be used advantageously in two ways when designing lacI studies. This is illustrated in Fig. 2. Each hyperbola represents hypothetical dose-time combinations giving the same limit of detection. Firstly, note the dramatic dose reduction possible with a relatively small increase in treatment period as one moves from a 1-day to a 4-week exposure period (for example, $1 \times 2.5 \mathrm{~g} / \mathrm{kg}$ and $25 \times 100 \mathrm{mg} / \mathrm{kg} /$ day both lie on the hyperbola corresponding to a $\mathrm{TD}_{10}$ detection limit of $10 \mathrm{mg} / \mathrm{kg} /$ day).

Secondly, note how the margin of safety offered by a negative lacI result increases with exposure time (Fig. 2, horizontal dotted line): the higher the corresponding $\mathrm{TD}_{10}$, the better the detection limit and the lower the maximum possible carcinogenic potency of a test chemical. For example, 2 days $\times 125 \mathrm{mg} / \mathrm{kg}$ gives a $T_{10}$ detection limit of only $1 \mathrm{mg} /$ $\mathrm{kg} /$ day, whereas 100 days $\times 125 \mathrm{mg} / \mathrm{kg}$ would increase the $\mathrm{TD}_{10}$ detection limit to 50 $\mathrm{mg} / \mathrm{kg} /$ day.

Obviously, the above comparison between lacI mutant frequency and carcinogenic potency would require a much larger data base than presently available before risk estimates could be based upon it. We are also aware that the factor of expression time has not been explicitly incorporated in this comparison, and that mutageniccarcinogenic potency comparisons should be calibrated separately for each organ. However, the purpose of the above discussion is to encourage a

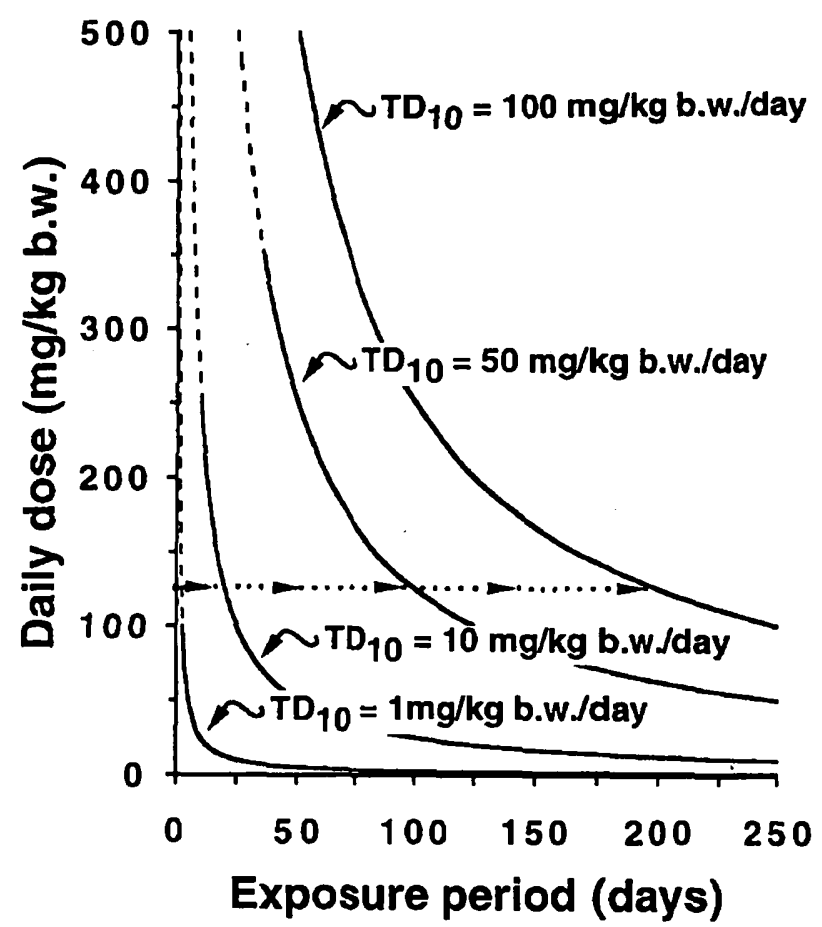

Fig. 2. Daily dose-exposure time combinations in the lacI test expected to produce approximately the same limit of detection $\left(\mathrm{TD}_{10}\right)$ as a 2-year rodent carcinogenicity study with daily doses of $1,10,50$ or $100 \mathrm{mg} / \mathrm{kg}$ body weight/day. The values along one hyperbola all have the same limit of detection. In the dashed regions, toxicity might result in deviations from these hypothetical curves. The dotted line illustrates the increase in detection limit (and margin of safety) which results from dosing at e.g. $125 \mathrm{mg} / \mathrm{kg}$ body weight/day for increasingly long time periods.

quantitative perspective when dealing with lacI data and to point out both the possibilities and limititations posed by current detection limits.

\section{References}

Cairns, T. (1979) The ED01 study: introduction, objectives, and experimental design, J. Environ. Path. Toxicol., 3, $1-7$.

Colnaghi, M.I., G. Della Porta, G. Parmiani and G. Caprio (1969) Chromosomal changes associated with urethane leukemogenesis in mice, Int. J. Cancer, 4, 327-333.

Frei, J.V., and S. Venitt (1975) Chromosome damage in the bone marrow of mice treated with the methylating agents methyl methanesulphonate and $N$-methyl- $N$-nitrosourea in the presence or absence of caffeine, and its relationship with thymoma induction, Mutation Res., 30, 89-96. 
Friedman, M.A., and J. Staub (1977) Induction of micronuclei in mouse and hamster bone-marrow by chemical carcinogens, Mutation Res., 43, 255-262.

Gold, L.S., T.H. Slone, N.B. Manley, G.B. Garfinkel, E.S. Hudes, L. Rohrbach and B.N. Ames (1991) The Carcinogenic Potency Database: analyses of 4000 chronic animal cancer experiments published in the general literature and by the U.S. National Cancer Institute/National Toxicology Program, Environ. Health Perspect., 96, 11-15.

Gunz, D., S.E. Shephard and W.K. Lutz (1993) Can nongenotoxic carcinogens be detected with the lacl transgenic mouse mutation assay?, Environ. Mol. Mutagen., 21, 209211.

Heddle, J.A., M. Hite, B. Kirkhart, K. Mavournin, J.T. MacGregor, G.W. Newell and M.F. Salamone (1983) The induction of micronuclei as a measure of genotoxicity, Mutation Res., 123, 61-118.

Hitachi, M., K. Yamada and S. Takayama (1975) Cytologic changes induced in rat liver cells by short-term exposure to chemical substances, J. Natl. Cancer Inst., 54, 1245-1247.

IARC (1978) Some $N$-Nitroso Compounds, IARC Monographs, 17, 125-175, 191-215, 227-255.

IARC (1987) Genetic and Related Effects: An updating of selected IARC Monographs from Volumes 1 to 42, IARC Monographs, Suppl. 6, 196-206.

Kohler, S.W., G.S. Provost, P.L. Kretz, A. Fieck, J.A. Sorge and J.M. Short (1990) The use of transgenic mice for short-term, in vivo mutagenicity testing, Genet. Anal. Tech. Appl., 7, 212-218.

Kohler, S.W., G.S. Provost, A. Fieck, P.L. Kretz, W.O. Bullock, D.L. Putman, J.A. Sorge and J.M. Short (1991a) Analysis of spontaneous and induced mutations in transgenic mice using a lambda ZAP/lacI shuttle vector, Environ. Mol. Mutagen., 18, 316-321.

Kohler, S.W., G.S. Provost, A. Fieck, P.L. Kretz, W.O. Bullock, J.A. Sorge, D.L. Putman and J.M. Short (1991b) Spectra of spontaneous and mutagen-induced mutations in the lacl gene in transgenic mice, Proc. Natl. Acad. Sci. USA, 88, 7958-7962.
NIOSH (1987) Registry of Toxic Effects of Chemical Substances, U.S. Dept. of Health \& Human Services/Natl. Inst. Occup. Safety and Health, Washington, DC.

Preston, R.J., W. Au, M.A Bender, J.G. Brewen. A.V. Carrano, J.A. Heddle, A.F. McFee, S. Wolff and J.S. Wassom (1981) Mammalian in vivo and in vitro cytogenetic assays: A report of the U.S. EPA's Gene-Tox Program, Mutation Res., 87, 143-188.

Russell, W.L., P.R. Hunsicker, D.A. Carpenter, C.V. Cornett and G.M. Guinn (1982) Effect of dose fractionation on the ethylnitrosourea induction of specific-locus mutations in mouse spermatogonia, Proc. Natl. Acad. Sci. USA, 79, 3592-3593.

Shephard, S.E., W.K. Lutz and C. Schlatter (1993) Mutations in liver DNA of lacl transgenic mice (Big Blue) following subchronic exposure to 2-acetylaminofluorene, Mutation Res., 302, 91-96.

Soukup, S.W., and W. Au (1975) The effect of ethylnitrosourea on chromosome aberrations in vitro and in vivo, Humangenetik, 29, 319-328.

Spiegel, M.R. (1990) Statistik, McGraw-Hill Europe, London, p. 124.

Tao, K.S., and J.A. Heddle (1994) The accumulation and persistence of somatic mutations, in preparation.

Tates, A.D., I. Neuteboom, A.H.M. Rotteveel, N. de Vogel, G.J. Menkveld and L. den Engelse (1986) Persistence of preclastogenic damage in hepatocytes of rats exposed to ethylnitrosourea, diethylnitrosamine, dimethylnitrosamine and methyl methanesulphonate. Correlation with DNA O-alkylation, Carcinogenesis, 7, 1053-1058.

Watanabe, M., S. Honda, M. Hayashi and T. Matsuda (1982) Mutagenic effects of combinations of chemical carcinogens and environmental pollutants in mice as shown by the micronucleus test, Mutation Res., 97, 43-48.

Werner, J. (1984) Medizinische Statistik, Urban \& Schwarzenberg, Munich. 